\title{
What is the evidence base to guide surgical treatment of infected hip prostheses? Systematic review of longitudinal studies in unselected patients
}

Andrew D Beswick ${ }^{*}$, Karen T Elvers' ${ }^{1}$, Alison J Smith¹, Rachael Gooberman-Hill1', Andrew Lovering ${ }^{2}$ and Ashley W Blom ${ }^{1}$

\begin{abstract}
Background: Prosthetic joint infection is an uncommon but serious complication of hip replacement. There are two main surgical treatment options, with the choice largely based on the preference of the surgeon. Evidence is required regarding the comparative effectiveness of one-stage and two-stage revision to prevent reinfection after prosthetic joint infection.

Methods: We conducted a systematic review to identify randomised controlled trials, systematic reviews and longitudinal studies in unselected patients with infection treated exclusively by one- or two-stage methods or by any method. The Embase, MEDLINE and Cochrane databases were searched up to March 2011. Reference lists were checked, and citations of key articles were identified by using the ISI Web of Science portal. Classification of studies and data extraction were performed independently by two reviewers. The outcome measure studied was reinfection within 2 years. Data were combined to produce pooled random-effects estimates using the FreemanTukey arc-sine transformation.

Results: We identified 62 relevant studies comprising 4,197 patients. Regardless of treatment, the overall rate of reinfection after any treatment was $10.1 \%(95 \% \mathrm{Cl}=8.2$ to 12.0). In 11 studies comprising 1,225 patients with infected hip prostheses who underwent exclusively one-stage revision, the rate of reinfection was $8.6 \%(95 \% \mathrm{Cl}=$ 4.5 to 13.9). After two-stage revision exclusively in 28 studies comprising 1,188 patients, the rate of reinfection was $10.2 \%(95 \% \mathrm{Cl}=7.7$ to 12.9$)$.

Conclusion: Evidence of the relative effectiveness of one- and two-stage revision in preventing reinfection of hip prostheses is largely based on interpretation of longitudinal studies. There is no suggestion in the published studies that one- or two stage methods have different reinfection outcomes. Randomised trials are needed to establish optimum management strategies.
\end{abstract}

Keywords: hip replacement, hip arthroplasty, infection, revision, systematic review

\section{Background}

Hip replacement is widely used to treat pain associated with diseased or damaged joints. During the one-year period between April 2009 and March 2010, there were 71,021 primary hip replacement operations recorded in

\footnotetext{
* Correspondence: andy.beswick@bristol.ac.uk

'School of Clinical Sciences, University of Bristol, Musculoskeletal Research Unit, Southmead Hospital, Southmead Road, Bristol, BS10 5NB, UK Full list of author information is available at the end of the article
}

the National Joint Registry for England and Wales [1]. In the United States in 2006, the estimated number of hospital discharges after hip replacement was 231,000 [2], with demand predicted to increase substantially [3].

Deep prosthetic joint infection is an uncommon but serious complication of hip replacement [4]. Estimated incidences in UK populations are $0.45 \%$ to $0.57 \%[5,6]$, and the estimated incidence is $0.88 \%$ in the United States [7]. Infections that occur within 2 years of surgery 
are usually surgically acquired [8]. Surgical site infections have a very negative effect on patients. Typically, patients describe extreme pain, prolonged immobilisation, isolation and insecurity, as well as feelings of hopelessness [9]. Deep infection of hip prostheses puts patients at risk for these problems, and, if untreated, they can result in severe pain, persistent dislocation and death [10].

Conservative treatment with prosthesis retention may be considered in early infection if there is no evidence of prosthesis loosening or significant damage to soft tissue, as well as for infections that can be treated with antibiotics [8]. Typical rates of hip infection clearance of $89 \%$ [11] and $87 \%$ [12] have been reported recently. However, the need for long-term and possibly lifelong antibiotic treatment is acknowledged [12]. Treatment with prosthesis retention is not recorded in the National Joint Registry for England and Wales, but typically about $19 \%$ of prosthetic hip infections may be treated by using this method [13].

For the majority of patients with prosthetic hip infection, further major operations are required in an attempt to clear infection and reduce the need for joint excision or amputation. Surgical revision involves prosthesis removal and debridement with either immediate (one-stage) or delayed (two-stage) joint replacement or with excision (Girdlestone procedure). In England and Wales, about 500 hip revision procedures per year are required as a consequence of infection with treatment in one-stage revision (30\%), two-stage revision (64\%) or excision (6\%) [1]. Twostage revision is traditionally regarded as being more effective in treating infection, which probably explains the preponderance of two-stage revisions. The requirement of an extra hospital admission and a further major surgical procedure, however, means that a two-stage revision may cost $70 \%$ more than a one-stage revision [14].

Patients who undergo a two-stage revision are left without a joint between stages, and this is associated with pain and considerable disability. The period between stages is typically 2 to 12 months. In some patients, health status and infection severity may indicate that one revision method is appropriate [4]. In many cases where there is no clear advantage of one surgical method over another, however, the decision about treatment is made at the discretion of the surgeon. Using systematic review methods, we explored the evidence base supporting these decisions. We aimed to review evidence on the effectiveness of one-stage and two-stage revision in preventing reinfection after prosthetic hip infection.

\section{Methods}

We used systematic review methods based on those described in the Cochrane Handbook for Systematic
Reviews of Interventions [15] and in accordance with the Meta-analysis of Observational Studies in Epidemiology (MOOSE) proposal for reporting systematic reviews and meta-analysis of observational studies [16]. A MOOSE checklist is shown in Additional file 1, Table A1.

We searched the Embase, MEDLINE and Cochrane databases up to March 2011 for reviews, longitudinal studies and clinical trials. The search strategy used in MEDLINE is shown in Additional file 1, Table A2. The search included terms relating to hip replacement, infection and revision and focused on one- and two-stage surgeries. Thus, the search should have identified all studies in patients receiving contemporary surgical treatment options. We also searched reference lists and performed a citation search of key articles in the ISI Web of Science portal. No language restrictions were applied, which is an important consideration with the perceived international interest in treatment of infected hip prostheses.

Results of searches were stored in an EndNote X3/4 database (Thomson Reuters, New York, NY, USA). One reviewer (ADB) scanned titles and abstracts. Potentially relevant articles were acquired, and inclusion decisions were made separately, by two reviewers (ADB and KTE). Ultimately, decisions on inclusion were based on consensus.

We aimed to classify studies as follows: systematic reviews, randomised controlled trials or longitudinal studies in all patients with infection treated exclusively by one- or two-stage methods or by a variety of methods (including some by one- and some by two-stage). Studies excluded from this analysis reported case series of methods in selected patients (subsamples of patients who received revision in one or two stages or patients with a specific infection), had no outcomes by intention to treat, reported data for hip and knee combined or did not include patients with less than 2 years of follow-up.

To assess whether this selection strategy affected outcomes, we also analysed 2-year outcomes in any groups of patients who had received either one- or two-stage revision. We did not include studies where patients were treated only by joint excision with no prosthesis replacement.

Data were extracted in duplicate by two reviewers (ADB and KTE), with discrepancies resolved by discussion. Good practice in systematic reviews includes contact with authors to obtain additional information [15]. We did not contact authors, however, as many studies were published over 20 years ago and therefore we did not anticipate a good response.

The outcome we considered was reinfection within 2 years. No attempt was made to distinguish reinfection with the same or a new pathogen. As small case series are prone to selection issues, we report all studies in 
Additional file 1, Table A3, but discuss larger longitudinal studies (50 or more patients) in detail. To compare outcomes between methods, we created pooled randomeffects estimates using the Freeman-Tukey arc-sine transformation to stabilise the variances.

\section{Results}

The progress of the review is shown in Additional file 1, Figure A1. In our searches of databases, reference lists and citations, we identified 523 articles, 168 of which were subsequently found to be potentially relevant to this review. After reading the full papers, we included 66 articles in the review. The papers that we excluded mainly were selected case series of a particular surgical method rather than longitudinal studies of infected hip prostheses. The reasons for exclusion and references to the excluded studies are detailed in Additional file 1, Figure A1, and the references given in the Additional material.

The following studies were included: two systematic reviews comparing one- and two-stage methods in longitudinal studies $[17,18]$, eleven studies (thirteen articles) of exclusively one-stage revisions (articles A1 to A13), twenty-eight studies (twenty-seven articles) of exclusively two-stage revisions (articles A14 to A40) and twenty-three studies (twenty-four articles) where treatments comprised one- or two-stage revisions and/or other surgical methods (articles A41 to A64). Two studies were randomised controlled trials evaluating use of antibiotic beads (article A30) or spacer (article A14), and groups were treated as separate studies. However, no randomised trials comparing one- and two-stage methods were identified.

The review article reported by Gallo and colleagues compared the outcomes of one-stage and two-stage revisions and excision arthroplasty in longitudinal studies [17]. The authors used systematic search methods but did not show the details of the 77 included studies published up to November 2006 in patients with hip and knee infections. The use of relative risks in their study indicates that the authors included studies where oneand two-stage methods were conducted in the same population. This approach does not address expected bias arising from selection of patients by health status and infection severity.

In their review, Wolf and colleagues reported an increased reinfection rate after one-stage revisions (12.3\%) compared with two-stage revisions (6.5\%) of infected total hip replacement [18]. In the studies they classified as two-stage revisions, however, more patients died. Searches up to May 2008 were limited to MEDLINE and publications in a major orthopaedic journal.

Longitudinal studies that we identified, regardless of size, are summarised in Additional file 1, Table A3. This includes descriptive information, our justifications for including the study as unselected (consecutive prosthetic hip infections) and the outcome as reflecting infection within 2 years of revision (if described). We also present an estimate of the 2-year reinfection rate in each study. Studies including 50 or more patients are summarised in Table 1.

The studies we included reported data from infected hips identified over extended periods with a mean of 8.5 years (range 3 to 17 years) for studies of exclusively one- or two-stage revisions. Generally, information on reinfection was clear, and, in some articles, data on individual patients was provided. Where possible, we used data on reinfection within 2 years of treatment, but this was not always the case.

\section{One-stage revisions}

Reinfection rates in the five studies with over 50 patients (range 72 to 640) were $15.5 \%$ [19], 8.9\% [20], $7.9 \%$ [21], 3.3\% [22] and 26.4\% [23]. In three of the studies, the use of antibiotic-loaded bone cement was studied $[19,20,22]$.

An early series described by Buchholz and colleagues included 640 revisions of infected hip prostheses treated exclusively by a one-stage procedure [19]. The authors reported "bad results," which included failure to eradicate infection and achievement of stable joint replacement. The authors reported a success rate of $77 \%$ after one-stage revision, with a stable, infection-free joint achieved in $90 \%$ of patients after further revision operations. By estimating an outcome related directly to infection, we calculated that $15.5 \%$ of patients had early reinfection. This may represent an overestimate, however, because we cannot be certain that all of these reinfections occurred within 2 years or that all second exchange operations were performed as a consequence of reinfection.

In 90 patients followed up by Loty and colleagues, the rate of reinfection within 2 years was $8.9 \%$ [20]. This may have been an underestimate, however, as seven patients $(7.8 \%)$ were lost to 2-year follow-up. Long-term function measured by the Merle d'Aubigné-Postel score was good or very good in $79 \%$ of patients followed up.

Miley and colleagues reported a study of 100 patients with 101 infections after hip surgery and reported outcomes from grades I to IV [21]. Grade IV, reflecting drainage, constant pain and the suggestion of a need for further surgery, was recorded in $7.9 \%$ of hips. The incidence of reinfection within 2 years was not specified. Raut and colleagues reported on a cohort of 183 patients, among whom the reinfection was $3.3 \%$ within 2 years of revision of infected hip replacement $[22,24]$. No pain, as measured by the Merle d'Aubigné-Postel score, was reported by $69 \%$ of patients at last follow-up. 
Table 1 Characteristics of included studies with $\mathbf{5 0}$ or more patients

\begin{tabular}{|c|c|c|c|c|}
\hline $\begin{array}{l}\text { Study } \\
\text { Country } \\
\text { Year of } \\
\text { study }\end{array}$ & $\begin{array}{l}\text { Patient treatments } \\
\text { Number of participants } \\
\text { Mean age ( } \% \text { men) }\end{array}$ & $\begin{array}{l}\text { Exclusive surgical method } \\
\text { Treatment }\end{array}$ & $\begin{array}{l}\text { Overall follow-up } \\
\text { Outcomes } \\
\text { Deaths and losses to follow-up }\end{array}$ & $\begin{array}{l}N(\%) \text { reinfection at } 2 \\
\text { years } \\
\text { Details }\end{array}$ \\
\hline \multicolumn{5}{|l|}{ One-stage } \\
\hline $\begin{array}{l}\text { Buchholz et } \\
\text { al., } 1981 \text { [19] } \\
\text { Germany } \\
1968 \text { to } 1977\end{array}$ & $\begin{array}{l}\text { Hip arthroplasty for } \mathrm{OA} \\
(95 \%) \text {, others }(5 \%) \\
N=640 \\
58.8 \text { years }(39.7 \%)\end{array}$ & $\begin{array}{l}\text { "Patients with deep infection } \\
\text { involving arthroplasties of the hip" (p. } \\
\text { 344). } \\
\text { Antibiotic-loaded cement }\end{array}$ & $\begin{array}{l}52 \text { months } \\
\text { Need for further exchange, } \\
\text { reinfection } \\
90 \text { deaths }\end{array}$ & $\begin{array}{l}99(15.5 \%) \\
\text { Reoperation due to "bad" } \\
\text { outcome plus other } \\
\text { infection-related outcomes }\end{array}$ \\
\hline $\begin{array}{l}\text { Loty et al., } \\
1992[20] \\
\text { France } \\
1980 \text { to } 1988\end{array}$ & $\begin{array}{l}\text { THR } \\
N=90 \\
65.7 \text { years (not specified) }\end{array}$ & $\begin{array}{l}\text { "We usually manage infected total hip } \\
\text { replacements by a one stage revision" } \\
\text { (p. 330). } \\
\text { Systemic antibiotics and antibiotic- } \\
\text { loaded cement }\end{array}$ & $\begin{array}{l}47 \text { months } \pm 29 \text { months } \\
\text { Reinfection, other failure, Merle } \\
\text { d'Aubigné-Postel score } \\
\text { Four deaths, seven lost to follow- } \\
\text { up }\end{array}$ & $\begin{array}{l}8(8.9 \%) \\
\text { Infections occurred } \\
\text { between } 6 \text { and } 24 \text { months }\end{array}$ \\
\hline $\begin{array}{l}\text { Miley et al., } \\
1982 \text { [21] } \\
\text { USA } \\
1969 \text { to } 1979\end{array}$ & $\begin{array}{l}\text { Hip surgery for fracture } \\
\text { dislocation }(47 \%), \text { OA } \\
(36 \%) \text {, others }(17 \%) \\
N=100 \text { (101 hips) } \\
\text { Men } 56.2 \text { years, women } 59 \\
\text { years }(53 \%)\end{array}$ & $\begin{array}{l}\text { "The operating surgeon must be } \\
\text { prepared to perform either of these } \\
\text { operations (1-stage or Girdlestone), } \\
\text { depending on the surgical findings } \\
\text { and medical work-up" (p79). } \\
\text { Intensive multiple-drug antimicrobial } \\
\text { programme }\end{array}$ & $\begin{array}{l}48.5 \text { months, minimum } 32 \\
\text { months } \\
\text { Grading system focusing on } \\
\text { quality of life and hip function. } \\
\text { Grade IV outcome: drainage, } \\
\text { constant pain, further surgery } \\
\text { suggested } \\
11 \text { deaths }\end{array}$ & $\begin{array}{l}\text { Eight hips (7.9\%) Grade IV } \\
\text { outcome } \\
\text { No information on } \\
\text { reinfection within } 2 \text { years }\end{array}$ \\
\hline $\begin{array}{l}\text { Raut et al., } \\
1995 \text { [22] } \\
\text { Wroblewski, } \\
1986[24] \\
\text { UK } \\
1979 \text { to } 1990\end{array}$ & $\begin{array}{l}\text { Cemented primary THR } \\
(63 \%) \text {, revision THR }(37 \%) \\
N=183 \\
64.5 \text { years }(48 \%)\end{array}$ & $\begin{array}{l}\text { "All infected arthroplasties during this } \\
\text { period were treated with 1-stage } \\
\text { reimplantation, irrespective of the } \\
\text { organism that was cultured, unless } \\
\text { the patient had poor quality bone } \\
\text { stock." (p. 202. Wroblewski, } 1986 \text { [24]) } \\
\text { Antibiotic-loaded cement }\end{array}$ & $\begin{array}{l}93 \text { months, range } 24 \text { to } 164 \\
\text { months } \\
\text { Persistent infection, Merle } \\
\text { d'Aubigné-Postel score (pain, } \\
\text { function and movement), } \\
\text { radiology, re-revision, } \\
\text { complications. } \\
14 \text { deaths ( } 0 \text { in year } 1)\end{array}$ & $\begin{array}{l}6(3.3 \%) \\
\text { Reinfection in first } 2 \text { years }\end{array}$ \\
\hline $\begin{array}{l}\text { Schneider, } \\
1989[23] \\
\text { Switzerland } \\
1973 \text { to } 1988\end{array}$ & $\begin{array}{l}\text { Hip implants } \\
N=72 \text { (excluding } 13 \\
\text { treated with irrigation } \\
\text { alone) } \\
\text { Not specified }\end{array}$ & $\begin{array}{l}\text { "Between } 1980 \text { and 1988, out of } 42 \\
\text { deep infections...." (p. 527) } \\
\text { Data also included from 1973 } \\
\text { onwards } \\
\text { Joint irrigation preceding revision }\end{array}$ & $\begin{array}{l}\text { Follow-up interval not specified. } \\
\text { Reinfection (bad outcome) }\end{array}$ & $\begin{array}{l}19(26.4 \%) \text {, rate from } 1980 \\
(16.1 \%) \\
\text { No information on } \\
\text { reinfection within } 2 \text { years }\end{array}$ \\
\hline \multicolumn{5}{|l|}{ Two-stage } \\
\hline $\begin{array}{l}\text { Chen et al., } \\
2009 \text { [25] } \\
\text { Taiwan } \\
1993 \text { to } 2005\end{array}$ & $\begin{array}{l}\text { THR (excluding patients } \\
\text { with proximal femoral } \\
\text { allograft reconstruction) } \\
N=57 \\
51.5 \text { years }(72 \%)\end{array}$ & $\begin{array}{l}\text { "[A]ccording to the protocol for short- } \\
\text { term parenteral antibiotics therapy at } \\
\text { this institution...." (p. 189). } \\
\text { Interim antibiotic-impregnated } \\
\text { cement beads }\end{array}$ & $\begin{array}{l}67.2 \text { months } \\
\text { Reinfection, Harris hip scores, } \\
\text { radiological examinations } \\
\text { Five deaths and five lost to } \\
\text { follow-up }\end{array}$ & $\begin{array}{l}7(12.3 \%) \\
\text { Reinfection in seven } \\
\text { patients after first stage } \\
\text { described in text }\end{array}$ \\
\hline $\begin{array}{l}\text { Fitzgerald } \\
\text { and Jones, } \\
1985[26] \\
\text { USA } \\
1969 \text { to } 1979\end{array}$ & $\begin{array}{l}\text { Hip implant } \\
N=131 \\
61 \text { years }(50 \%)\end{array}$ & $\begin{array}{l}\text { "[D]elayed reconstruction in } 131 \\
\text { patients who had an infection after a } \\
\text { previous total hip arthroplasty...." } \\
\text { (p.828. McDonald et al. } 1989 \text { [32]). } \\
\text { Intensive } \\
\text { Cemented reconstruction with no } \\
\text { added antibiotic }\end{array}$ & $\begin{array}{l}49 \text { months; range } 2 \text { to } 9 \text { years } \\
\text { Reinfection }\end{array}$ & $\begin{array}{l}\text { All hip implants } \\
11(8.4 \%) \\
\text { Reinfection up to } 429 \text { days }\end{array}$ \\
\hline $\begin{array}{l}\text { McDonald et } \\
\text { al., } 1989 \text { [32] } \\
1969 \text { to } 1985\end{array}$ & $\begin{array}{l}\text { Specifically THR for OA } \\
(69 \%) \text {, fracture }(13 \%), \text { other } \\
(18 \%) \\
N=81 \text { (including } \\
\text { additional } 13 \text { patients) } \\
60.0 \text { years }(53 \%)\end{array}$ & & $\begin{array}{l}5.5 \text { years, range } 2.0 \text { to } 13.6 \text { years } \\
\text { Reinfection, complications }\end{array}$ & $\begin{array}{l}\text { THR only } \\
6(7.4 \%) \text { estimated from } \\
\text { survival curve }\end{array}$ \\
\hline $\begin{array}{l}\text { Haddad et } \\
\text { al., } 2000 \text { [27] } \\
\text { UK } \\
1988 \text { to } 1992\end{array}$ & $\begin{array}{l}\text { THR for OA }(72 \%), \text { other } \\
(28 \%) \\
N=50 \\
60 \text { years }(46 \%)\end{array}$ & $\begin{array}{l}\text { "[C]onsecutive patients all of whom } \\
\text { were referred with an infected total } \\
\text { hip replacement and treated using a } \\
\text { standardised protocol" (p. 689). } \\
\text { Antibiotic-loaded beads and cement } \\
\text { ball } \\
\text { Uncemented }\end{array}$ & $\begin{array}{l}5.8 \text { years, range } 2 \text { to } 8.7 \text { years } \\
\text { Reinfection, Harris hip score, } \\
\text { radiological outcome, } \\
\text { complications } \\
\text { Two deaths }\end{array}$ & $\begin{array}{l}4(8 \%) \\
\text { No information on } \\
\text { reinfection within } 2 \text { years }\end{array}$ \\
\hline
\end{tabular}


Table 1 Characteristics of included studies with $\mathbf{5 0}$ or more patients (Continued)

\begin{tabular}{ll}
\hline Hsieh et al., & Prosthetic hip \\
2009 [28] & $N=99$ \\
Taiwan & 61 years (61\%) \\
2002 to 2005 &
\end{tabular}

$\begin{array}{ll}\text { Romanò et } & \text { Hip prostheses } \\ \text { al., 2010 [29] } & N=102 \\ \text { Italy } & 58 \text { years (34\%) } \\ \text { 2000 to 2007 } & \end{array}$

Stockley et THR for OA (60\%), al., 2008 [30] posttraumatic arthritis UK 1991 to $2004 \quad N=114$ 64 years (55\%)

Toulson et THR al., 2009 [31] $\quad N=132$

USA 54.7 years $(59 \%)$ in patients

1989 to 2003 "who completed the entire protocol" (p.1054)

\begin{abstract}
"The use of an ALCS in SEA for PHI has been a routine practice in our institution" (p. 93)
\end{abstract}

Antibiotic-loaded cement spacer

\section{"102 consecutive patients underwent two-stage revision of septic hip} replacement" (p. 26). antibiotic-loaded cement spacers Cementless

"[C]onsecutive patients with microbiologically-proven deep chronic infection of the hip were managed by a two-stage exchange procedure" (p.145) Antibiotic-loaded cement beads "All 132 cases of infected THAs treated at our institution...." (p.1052).

Spacer containing antibiotic impregnated cement used in 67\% (n)
Long-stem or short-stem preformed

43 months, range 24 to 60

months

Reinfection, Merle d'Aubigné-

Postel score (only in comparisons

of antibiotic strategies),

radiographic results

Three deaths, five lost to followup

48 months

Reinfection, Harris hip score (only

in comparisons of antibiotic

strategies)

Three deaths, nine lost to follow-

up

74 months, range 2 to 175

months

Reinfection

64.8 months, range 24 to 203 months; eight patients followed for only an average of 7.2 months

Reinfection, Harris hip score (mean only)

34 deaths (2 with no infection

information), 8 lost to follow-up

One-stage $(n=24)$, two-stage $(n=$ 55)

Some patients had spacers between stages

One-stage $(n=235)$, two-stage $(n=$

61)

Antibiotic-loaded cement pellets used in two-stage method

Mean 3.8 years (SD 2.2)

Reinfection, Harris hip score including limping and walking, radiographic outcome Seven lost to follow-up

Not specified

Reinfection, mechanical survival, radiological outcome

\section{Combination}

of methods

\section{De Man et THR}

al., 2011 [33] $\quad N=79$ hips

Switzerland 70 years (57\%) in patients

1985 to 2004 followed up

\section{Elson, 1993 THR

$\begin{array}{ll}\text { [34] } & N=296 \text { (definite or } \\ \text { UK } & \text { possible infection) }\end{array}$

Not specified Not specified
One-stage $(n=21)$, two-stage $(n=$ 161), no reimplantation $(n=25)$ Gentamicin cement

Germany 69 years (42\%)

1976 to 1986

Ladero THR

Morales et al., $N=62$ (another 12 with 1999 [36] nonsurgical treatment) Spain $\quad 74$ years (53\%)

1985 to 1995

Lecuire et al., THR

1999 [37] $\quad N=57$

France $\quad 70.6$ years

1982 to 1997

Oussedik et THR

al., $2010[38] \quad N=50$

UK 65 years (42\%)

1999 to 2002
One-stage $(n=2)$, two-stage $(n=37), 4.8$ years

resection-only $(n=23)$

Some treated after introduction of perioperative antibiotic protocol

One-stage $(n=16)$, two-stage $(n=$ 41)

Uncemented

One-stage $(n=11)$, two-stage $(n=$ 39)

Antibiotic-loaded spacer used in twostage

Gentamicin-loaded cement used in one-stage

6.6 years
32 months

Reinfection, function

Reinfection, Merle d'Aubigné-

Postel score, clinical and

functional outcome (pain, mobility, gait)

Reinfection, Merle d'Aubigné-

Postel scale, Harris hip score

6.8 years, range 5.5 to 8.8 years satisfaction
$8(8.1 \%)$

Reinfection between stages

$5(4.9 \%)$ (including between stages)

$9(7.9 \%)$

Reinfection within 1 year

$11(8.3 \%)$

Three new infections within 24 months, four infections not eradicated, four patients who died had infections

Overall $(n=2,2.5 \%)$

One-stage $(n=1,4.5 \%)$

Two-stage $(n=1,2.0 \%)$

Overall $(n=36,12.2 \%)$

One-stage $(n=33,14.0 \%)$

Two-stage $(n=3,4.9 \%)$

Time of definite or possible reinfection (mean 25 months, range 1 to 68 months)

Overall $(n=24,11.6 \%)$

One-stage $(n=7,33.3 \%)$

Two-stage ( $n=17,10.6 \%)$

Time of reinfection unclear

Overall $(n=3,4.8 \%)$

One-stage $(n=0,0 \%)$ Reinfection, Harris hip score, VAS

Two-stage $(n=3,8.1 \%)$

Time of reinfection unclear

Overall $(n=2,3.5 \%)$

One-stage $(n=1,6.3 \%)$

Two-stage $(n=1,2.4 \%)$

Time of reinfection unclear

Overall $(n=2,4.0 \%)$

One-stage $(n=0,0 \%)$

Two-stage $(n=2,5.1 \%)$

No information on

reinfection within 2 years 
Table 1 Characteristics of included studies with $\mathbf{5 0}$ or more patients (Continued)

\begin{tabular}{|c|c|c|c|c|}
\hline $\begin{array}{l}\text { Sanzén et al., } \\
1988 \text { [39] } \\
\text { Carlsson et } \\
\text { al., } 1978 \text { [42] } \\
\text { Sweden } \\
1974 \text { to } 1981\end{array}$ & $\begin{array}{l}\text { THR for } \mathrm{OA}(74 \%), \\
\text { congenital dislocation }(8 \%), \\
\text { fracture }(8 \%), \text { others }(10 \%) \\
N=108(110 \text { hips) } \\
64 \text { years }(53 \%)\end{array}$ & $\begin{array}{l}\text { One-stage ( } n=78 \text { hips), 2-stage ( } n= \\
32 \text { hips) } \\
\text { In } 44 \% \text { of two-stage procedures, } \\
\text { gentamicin-loaded PMMA beads were } \\
\text { used } \\
\text { Gentamicin-loaded cement }\end{array}$ & $\begin{array}{l}71 \text { months, range } 24 \text { to } 117 \\
\text { months } \\
\text { Reinfection, loosening, function } \\
\text { Eight deaths within } 24 \text { months }\end{array}$ & $\begin{array}{l}\text { Overall }(n=22,20.0 \%) \\
\text { One-stage }(n=17,21.8 \%) \\
\text { Two-stage }(n=8,25.0 \%) \\
\text { At least } 22 \text { of } 25 \\
\text { reinfections in first year }\end{array}$ \\
\hline $\begin{array}{l}\text { Vielpeau and } \\
\text { Lortat-Jacob, } \\
2002[40] \\
\text { France } \\
\text { Up to } \\
\text { December } \\
1998\end{array}$ & $\begin{array}{l}\text { THR } \\
N=458 \text { (including } \\
\text { acetabular or femoral } \\
\text { revision only, excluding } \\
\text { methods with retention of } \\
\text { components) } \\
\text { No age or sex details }\end{array}$ & $\begin{array}{l}\text { One-stage ( } n=127) \text {, two-stage ( } n= \\
\text { 222), resection }(n=81) \\
\text { Antibiotic cement }(n=249) \text {, no } \\
\text { antibiotic cement }(n=100) \text { in one or } \\
\text { two stages }\end{array}$ & $\begin{array}{l}\text { Median } 3 \text { years, } 81.5 \% \text { followed } \\
\text { for minimum of } 2 \text { years } \\
\text { Reinfection, complications }\end{array}$ & $\begin{array}{l}\text { Overall }(n=72,15.7 \%) \\
\text { One-stage }(n=15,11.8 \%) \\
\text { Two-stage }(n=33,14.9 \%)\end{array}$ \\
\hline
\end{tabular}

ALCS, antibiotic-loaded cement spacer; OA, osteoarthritis; PHI, prosthetic hip infection; PMMA, polymethylmethacrylate; SEA, staged exchange arthroplasty; THA, total hip arthroplasty; THR, total hip replacement; VAS, Visual Analogue Scale.

Thirteen percent of patients were dissatisfied with their outcomes.

Schneider followed up 72 patients with infected hip implants [23]. A bad outcome, mainly reinfection, was reported in $26.4 \%$ of patients, but this may have included those with reinfection after 2 years. The author reported that the reinfection rate in patients with infection identified from 1980 onwards was $16.1 \%$.

\section{Two-stage revisions}

Seven studies of 50 or more patients reported outcomes of two-stage revisions of infected hip prostheses. The reinfection rates reported were $12.3 \%$ [25], 8.4\% [26], 8.0\% [27], 8.1\% [28], 4.9\% [29], 7.9\% [30] and 8.3\% [31]. Antibiotic-loaded cement beads $[25,27,30]$ or spacers $[28,29,31]$ were used between stages in six studies.

Chen and colleagues reported a 2-year reinfection rate of $12.3 \%$ after treatment of infected hip replacement [25]. This was mainly restricted to the period between stages, with repeated debridements used to achieve a lower proportion of patients with infection at 2 years (3.5\%). An excellent or good functional recovery according to the Harris hip score was recorded in $74 \%$ of patients. In a study of 131 patients with infected hip implants, Fitzgerald and Jones reported a reinfection rate within 14 months of $8.4 \%$ [26,32]. Haddad and colleagues followed up 50 patients with infected hip replacement and reported reinfection in $8.0 \%$ of them [27]. It was not clear whether these reinfections occurred within 2 years of hip replacement. A good or excellent functional outcome according to the Harris hip score was achieved by $78 \%$ of patients.

In a study of 99 patients with infected hip prostheses, Hsieh and colleagues reported reinfection between stages in $8.1 \%$ of patients [28]. Romanò and colleagues followed up 102 patients with infected hip prostheses [29]. Within 3 years of revision, $4.9 \%$ of patients had reinfection. A further $8.8 \%$ of patients were lost to follow-up. In a study of 114 patients with infected total hip replacement, Stockley and colleagues reported reinfection within 1 year in $7.9 \%$ of patients [30]. Toulson and colleagues reported reinfection in $8.3 \%$ of patients within 2 years of total hip replacement [31].

\section{Studies with combination of one-stage, two-stage and excision procedures}

In addition to the studies of specifically one-stage and two-stage revisions, searches identified studies in which patients with infected hip prostheses were followed up after treatment by any one of one-stage, two-stage or excision methods. In eight studies of 50 or more patients, the rates of reinfection were $2.5 \%$ [33], 12.2\% [34], 11.6\% [35], 4.87\% [36], 3.5\% [37], 4.0\% [38], 20.0\% [39] and 15.7\% [40]. Four of these studies had sufficient one-stage and two-stage revisions to compare reinfection outcomes.

Elson reported almost three times the rate of reinfection over a range of 1 to 68 months after one-stage as two-stage revisions [34]. He did not present information on patient characteristics, however, and acknowledged that the difference in infection rates represented "an oversimplification of the many complex factors involved in the analysis of these results" [41] (p. 761).

Ketterl and colleagues reported a threefold increase in the risk of reinfection in patients treated with one-stage revision compared with two-stage revision [35]. Again, no information was provided regarding the characteristics of patients who underwent procedures using the different revision methods. Also, no information was provided on patients who did not receive implantation in a planned two-stage procedure. If these were classified as failed two-stage revisions, the reinfection rate would increase from $10.6 \%$ to $26.1 \%$.

In the large, multicentre study comprising 458 patients with surgical revision reported by Vielpeau and Lortat-Jacob, the rate of reinfection in patients who underwent one-stage revision was $11.8 \%$ compared with $14.9 \%$ in those who underwent two-stage revision [40]. 
In that study, no information was provided on reinfection within 2 years specifically, and about $18 \%$ of patients died or were lost to follow-up.

Sanzen and colleagues reported a $13 \%$ reduction in reinfection in patients who received a one-stage compared with a two-stage replacement [39]. Unlike the reporters of the previous studies, these authors described the process by which patients were allocated to one- or two-stage revision; in the earlier years of their study, treatment at one hospital was by one-stage revisions and in two hospitals by two-stage procedures [42].

\section{Comparison of methods}

To compare methods, we included all studies with reinfection outcomes, regardless of the number of patients studied. Point estimates and confidence intervals for the proportions of patients with reinfection are shown in Figure 1.

In the 11 studies of exclusively one-stage revision comprising 1,225 patients, the pooled-effect estimate of incidence of reinfection using a random-effects model was $8.6 \%$ (95\% CI $=4.5$ to 13.9$)$. Substantial heterogeneity was evident among the studies $\left(\chi^{2}=59.06, d f=10\right.$, $\left.P=0.000, I^{2}=83.1 \%\right)$. In a fixed-effects analysis, the pooled incidence rate was $11.4 \%$ (95\% CI $=9.7$ to 13.3$)$. The discrepancy with the random-effects model was mainly explained by the large study of Buchholz and colleagues. Excluding this study, with its less specific outcome measure of the need for second exchange and other reinfections, the pooled random-effects estimate was $7.7 \%$ (95\% CI $=3.6$ to 13.4$)$ and heterogeneity was reduced slightly $\left(\chi^{2}=39.61, d f=9, P=0.000, I^{2}=\right.$ 77.3\%).

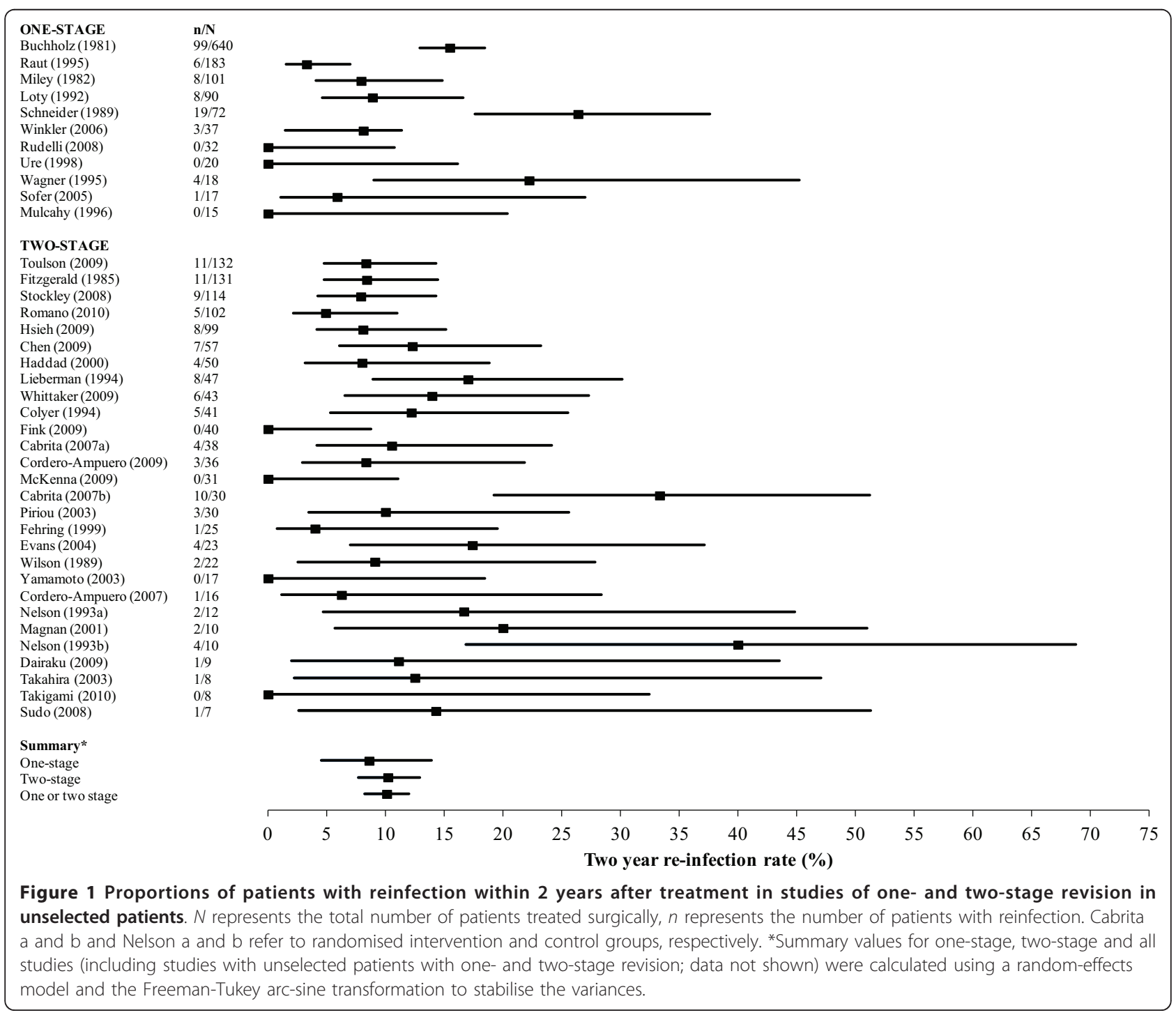


In the 28 studies comprising 1,188 patients treated exclusively with two-stage revision, the pooled randomeffects estimate for the incidence of reinfection was $10.2 \%$ ( $95 \% \mathrm{CI}=7.7$ to 12.9 ). The heterogeneity among studies was moderate $\left(\chi^{2}=51.73, d f=27, P=0.003, I^{2}\right.$ $=47.8 \%$ ).

Overall, across the 62 studies comprising 4,197 unselected patients (or hips) treated for prosthesis infection, the reinfection incidence using a random-effects model was $10.1 \%$ ( $95 \% \mathrm{CI}=8.2$ to 12.0$)$ with substantial heterogeneity $\left(\chi^{2}=209.42, d f=61, P=0.000, I^{2}=70.9 \%\right)$.

We also took the opportunity to compare reinfection rates for all the studies we identified that reported reinfection rates after one- and two-stage revision procedures. This included patients selected by a surgeon for a particular method on the basis of health status and infectious agent. The results of 133 studies comprising 5,556 patients are summarised in Additional file 1, Figure A2. In a random-effects analysis, the rates of reinfection after one- and two-stage revisions were $10.56 \%$ (95\% CI $=8.12$ to 13.31$)$ and $8.71 \%(95 \% \mathrm{CI}=7.32$ to 10.17), respectively. Overall, across all studies of surgical revision using one- and two-stage methods, the rate of reinfection was $9.19 \%$ (95\% CI $=7.96$ to 10.50$)$. Heterogeneity was moderate $\left(\chi^{2}=289.67, d f=132, P=0.000\right.$, $\left.I^{2}=54.4 \%\right)$.

\section{Discussion}

About 10\% of surgical revision procedures for infected hip prostheses become reinfected within 2 years. Pooled estimates of reinfection outcomes with wide confidence intervals do not suggest that outcomes are worse after one-stage compared with two-stage revision.

Evidence on the relative effectiveness of one- and twostage revisions in preventing reinfection of hip prostheses is largely based on interpretation of longitudinal studies. Reviews of longitudinal studies and particularly case series are limited by the possibility of publication bias and other sources of bias. We used systematic review methods to identify studies that described outcomes specifically after one- or two-stage revisions in consecutive and generally unselected patients.

Despite our aim to include only studies of unselected patients undergoing surgical revision, we recognise an earlier phase of selection related to management without further replacement. Different protocols, eligibility criteria and use of treatments with prosthesis retention may affect the representativeness of the study populations we included and may explain the high degree of statistical heterogeneity we observed. As is true of a review of treatment of infected knee prostheses by Jämsen and colleagues, however, we believe that it is important to attempt to include "only papers reporting a pure series of either one-stage or two-stage revision" [43] (p.
72). This is supported by the somewhat different reinfection rates we observed when we included studies that included patients selected for a particular revision method on the basis of infection severity and other aspects of patient health.

In this overview of studies in unselected patients, we specified prevention of reinfection as the key aim of revision surgery. In discussions with our advisory group of patients with joint replacement, patients recognised that clearance of infection is of paramount importance. Achievement of a functional, painless hip is the aim of any revision hip replacement [44], however, and the importance of patient-reported outcomes in assessing joint replacement outcome is widely recognised [45]. In their review, Wolf and colleagues explored patient preferences for one- or two-stage revision in a Markov simulation model [18]. In addition to outcomes reported in longitudinal studies, they used data collected from nonorthopaedic outpatients on trade-offs between impaired health versus full health with shortened life, as well as time with constant severe pain. They concluded that, compared to a two-stage procedure, one-stage revision was associated with greater benefit in terms of quality-adjusted life years.

One- and two-stage methods are perceived to have specific advantages and disadvantages. With a one-stage approach and a single major surgery, recovery is quicker. The advantages of two-stage treatment relate to the opportunity to apply an enhanced antimicrobial strategy between excision and reimplantation surgeries. The results of bacteriological samples obtained at surgery can be used to guide antibiotic treatment, and the period between stages is an opportunity for insertion of antibiotic-impregnated cement beads into the joint space. In two-stage revisions, however, patients experience considerable restriction of movement during the period between implant removal and replacement [4]. Two-stage revision is often considered essential for more virulent infections. Nevertheless, Leung and colleagues reported a reinfection rate of $21 \%$ after twostage revision in patients with resistant infections [46].

To reduce long-term problems resulting from an extended period without an implant, an antibioticimpregnated cement "spacer" may be used to maintain some function and a correct leg length and to reduce long-term problems associated with disuse. Although spacers improve patient mobility, complications can arise. For example, in 88 spacer implantations performed by Jung and colleagues, there were 15 spacer dislocations (17\%), 9 spacer fractures (10\%) and an overall complication rate of 58.5\% [47].

The economic implications of uncomplicated one- and two-stage revision differ considerably. Although a onestage procedure may require a prolonged hospital stay 
to facilitate intravenous antibiotic therapy, the main determinant of cost is the requirement for additional surgery in a two-stage revision. In the United Kingdom, the cost to the NHS of each complicated hip procedure is over $£ 8,000$ [48]. Klouche and colleagues estimated that the cost of managing a patient with an infected hip prosthesis is 3.6 times greater than that of a primary total hip replacement and that two-stage revisions cost 1.7 times more than one-stage revisions [14].

Forty-three years of data collection do not conclusively support a specific treatment for prosthetic hip infection. The thoroughness of data collected over extended periods suggests the possibility of individual patient data synthesis with time-to-event analyses [49]. We concur with Matthews and colleagues, however, that large, multicentre, randomised trials are needed to establish optimum management strategies [4], and this is particularly apparent regarding surgical options. It could be argued that appropriate randomised trials are not feasible because of the limited opportunities of an individual surgeon to gain experience in using a particular technique. However, the surgical techniques familiar to surgeons operating with the more widely used two-stage strategy and with aseptic revision (a single-stage revision) include most of the skills required.

The acceptability to patients of methods and their evaluation is of overriding importance. It is notable that only two studies collected data regarding patient-centred outcomes. If reinfection rates are similar between methods, the possibility of a single major surgery, reduced overall hospitalisation and avoidance of a prolonged period without a permanent implant would make a onestage procedure preferable. Conversely, it could be argued that the long-term, targeted antibiotic regimen associated with contemporary two-stage treatment should not be withheld.

Prosthetic hip infection is sufficiently rare to make a single, definitive randomised trial unlikely. Conducting multiple smaller trials in which patients' experiences and patient-reported outcomes are recorded, together with a systematic overview of infection outcome, may be a more valid approach, and this would also allow exploration of methodological variability and other sources of heterogeneity [50]. Research into the patient experience of prosthetic hip infection and its treatment is urgently required. This will help in the development of studies that identify the best method for treatment of prosthetic joint infection.

\section{Conclusions}

Evidence of the relative effectiveness of one- and twostage surgical revision in treatment of infected hip prostheses is largely based on interpretation of longitudinal studies. There is no suggestion on the basis of systematic review of published studies that one- or two-stage methods have different reinfection outcomes. Randomised trials are needed to establish optimum management strategies.

\section{Additional material}

Additional file 1: Table A1 Meta-analysis of Observational Studies in Epidemiology checklist. Table A2 Search strategy as applied in MEDLINE. Table A3 Characteristics of all included longitudinal studies regardless of size. Figure A1 Systematic review flow diagram. Figure A2 Proportions of patients with reinfection within 2 years in all studies including patients treated by one- and two-stage revision. Appendix References.

\section{Acknowledgements}

Five authors' current positions (ADB, KTE, RGH, AJS and AWB) are funded within a programme of independent research commissioned by the UK's National Institute for Health Research (NIHR) under its Programme Grants for Applied Research funding scheme (RP-PG-0407-10070). The views expressed are those of the authors and not necessarily those of the NHS, the NIHR or the Department of Health.

\section{Author details}

'School of Clinical Sciences, University of Bristol, Musculoskeletal Research Unit, Southmead Hospital, Southmead Road, Bristol, BS10 5NB, UK. ${ }^{2}$ Department of Microbiology, North Bristol NHS Trust, Bristol Centre for Antimicrobial Research and Enterprise, Southmead Hospital, Southmead Road, Bristol, BS9 3HU, UK.

\section{Authors' contributions}

AWB, ADB, RGH, AL and AJS conceived and designed the study. ADB and KTE conducted the systematic review. AJS conducted the statistical analysis. ADB drafted the manuscript with contributions from AWB, KTE, RGH, AJS and $\mathrm{AL}$. All authors read and approved the final version of the manuscript.

\section{Competing interests}

The authors declare that they have no competing interests.

Received: 3 January 2012 Accepted: 16 February 2012

Published: 16 February 2012

\section{References}

1. National Joint Registry for England and Wales (NJR): 7th Annual Report 2010 Hemel Hempstead: NJR Centre; 2010 [http://www.njrcentre.org.uk/ NirCentre/Portals/0/NJR\%207th\%20Annual\%20Report\%202010.pdf].

2. DeFrances CJ, Lucas CA, Buie VC, Golosinskiy A: 2006 National Hospital Discharge Survey. Natl Health Stat Report 2008, 5:1-20.

3. Kurtz S, Ong K, Lau E, Mowat F, Halpern M: Projections of primary and revision hip and knee arthroplasty in the United States from 2005 to 2030. J Bone Joint Surg Am 2007, 89:780-785.

4. Matthews PC, Berendt AR, MCNally MA, Byren I: Diagnosis and management of prosthetic joint infection. BMJ 2009, 338:b1773.

5. Blom AW, Taylor AH, Pattison G, Whitehouse S, Bannister GC: Infection after total hip arthroplasty: the Avon experience. J Bone Joint Surg $\mathrm{Br}$ 2003, 85:956-959.

6. Phillips JE, Crane TP, Noy M, Elliott TSJ, Grimer RJ: The incidence of deep prosthetic infections in a specialist orthopaedic hospital: a 15-year prospective survey. J Bone Joint Surg Br 2006, 88:943-948.

7. Kurtz SM, Lau E, Schmier J, Ong KL, Zhao K, Parvizi J: Infection burden for hip and knee arthroplasty in the United States. J Arthroplasty 2008, 23:984-991.

8. Zimmerli W, Trampuz A, Ochsner PE: Prosthetic-joint infections. N Engl J Med 2004, 351:1645-1654. 
9. Andersson AE, Bergh I, Karlsson J, Nilsson K: Patients' experiences of acquiring a deep surgical site infection: an interview study. Am J Infect Control 2010, 38:711-717.

10. Hunter G, Dandy D: The natural history of the patient with an infected total hip replacement. J Bone Joint Surg Br 1977, 59:293-297.

11. Vilchez F, Martínez-Pastor JC, García-Ramiro S, Bori G, Maculé F, Sierra J, Font L, Mensa J, Soriano A: Outcome and predictors of treatment failure in early post-surgical prosthetic joint infections due to Staphylococcus aureus treated with debridement. Clin Microbiol Infect 2011, 17:439-444.

12. Byren I, Bejon P, Atkins BL, Angus B, Masters S, McLardy-Smith P, Gundle R, Berendt $A$ : One hundred and twelve infected arthroplasties treated with 'DAIR' (debridement, antibiotics and implant retention): antibiotic duration and outcome. J Antimicrob Chemother 2009, 63:1264-1271.

13. Maurer TB, Zimmerli W, Ochsner PE: The role of a treatment algorithm to guide one- or two-stage exchange in periprosthetic hip joint infection [abstract S09.6]. J Bone Joint Surg Br 2011, 93(Suppl III):331-332.

14. Klouche S, Sariali E, Mamoudy P: Total hip arthroplasty revision due to infection: a cost analysis approach. Orthop Traumatol Surg Res 2010, 96:124-132.

15. In Cochrane Handbook for Systematic Reviews of Interventions version 5.1.0. (updated March 2011). Edited by: Higgins JPT, Green S. The Cochrane Collaboration; 2011:[http://www.cochrane-handbook.org/].

16. Stroup DF, Berlin JA, Morton SC, Olkin I, Williamson GD, Rennie D, Moher D Becker BJ, Sipe TA, Thacker SB, the Meta-analysis of Observational Studies in Epidemiology (MOOSE) Group: Meta-analysis of observational studies in epidemiology: a proposal for reporting. JAMA 2000, 283:2008-2012.

17. Gallo J, Smizanský M, Radová L, Potomková J: [Comparison of therapeutic strategies for hip and knee prosthetic joint infection] [in Czech]. Acta Chir Orthop Traumatol Cech 2009, 76:302-309.

18. Wolf CF, Gu NY, Doctor JN, Manner PA, Leopold SS: Comparison of one and two-stage revision of total hip arthroplasty complicated by infection: a Markov expected-utility decision analysis. J Bone Joint Surg Am 2011, 93:631-639.

19. Buchholz H, Elson R, Engelbrecht E, Lodenkämper H, Röttger J, Siegel A Management of deep infection of total hip replacement. J Bone Joint Surg Br 1981, 63:342-353.

20. Loty B, Postel M, Evrard J, Matron P, Courpied JP, Kerboull M, Tomeno B [One stage revision of infected total hip replacements with replacement of bone loss by allografts: study of 90 cases of which 46 used bone allografts] [in French]. Int Orthop 1992, 16:330-338.

21. Miley GB, Scheller AD, Turner RH: Medical and surgical treatment of the septic hip with one-stage revision arthroplasty. Clin Orthop Relat Res 1982 170:76-82

22. Raut $W$, Siney PD, Wroblewski BM: One-stage revision of total hip arthroplasty for deep infection: long-term followup. Clin Orthop Relat Res 1995, 321:202-207.

23. Schneider R: [The infected total prosthesis] [in German]. Orthopade 1989, 18:527-532.

24. Wroblewski BM: One-stage revision of infected cemented total hip arthroplasty. Clin Orthop Relat Res 1986, 211:103-107.

25. Chen WS, Fu TH, Wang JW: Two-stage reimplantation of infected hip arthroplasties. Chang Gung Med J 2009, 32:188-197.

26. Fitzgerald $\mathrm{RH}$, Jones DR: Hip implant infection: treatment with resection arthroplasty and late total hip arthroplasty. Am J Med 1985, 78:225-228.

27. Haddad FS, Muirhead-Allwood SK, Manktelow AR, Bacarese-Hamilton I: Twostage uncemented revision hip arthroplasty for infection. J Bone Joint Surg Br 2000, 82:689-694

28. Hsieh PH, Huang KC, Lee PC, Lee MS: Two-stage revision of infected hip arthroplasty using an antibiotic-loaded spacer: retrospective comparison between short-term and prolonged antibiotic therapy. J Antimicrob Chemother 2009, 64:392-397.

29. Romanò CL, Romanò D, Logoluso N, Meani E: Long-stem versus shortstem preformed antibiotic-loaded cement spacers for two-stage revision of infected total hip arthroplasty. Hip Int 2010, 20:26-33.

30. Stockley I, Mockford BJ, Hoad-Reddick A, Norman P: The use of two-stage exchange arthroplasty with depot antibiotics in the absence of longterm antibiotic therapy in infected total hip replacement. J Bone Joint Surg Br 2008, 90:145-148.

31. Toulson C, Walcott-Sapp S, Hur J, Salvati E, Bostrom M, Brause B, Westrich GH: Treatment of infected total hip arthroplasty with a 2-stage reimplantation protocol: update on "our institution's" experience from 1989 to 2003. J Arthroplasty 2009, 24:1051-1060.

32. McDonald DJ, Fitzgerald RH Jr, Ilstrup DM: Two-stage reconstruction of a total hip arthroplasty because of infection. J Bone Joint Surg Am 1989, 71:828-834.

33. De Man FH, Sendi P, Zimmerli W, Maurer TB, Ochsner PE, Ilchmann T: Infectiological, functional, and radiographic outcome after revision for prosthetic hip infection according to a strict algorithm. Acta Orthop 2011, 82:27-34.

34. Elson RA: One-stage exchange in the treatment of the infected total hip arthroplasty. Semin Arthroplasty 1994, 5:137-141.

35. Ketterl R, Henly MB, Stübinger B, Beckurts T, Claudi B: Analysis of three operative techniques for infected total hip replacements. Orthop Trans $1988,12: 715$.

36. Ladero Morales F, Fernandez Gonzalez J, Blanco Ortiz F, Martinez Martin J, Garcia Araujo C: [Treatment of infected hip arthroplasty: retrospective study] [in Spanish]. Rev Ortop Traumatol 1999, 43:84-92.

37. Lecuire F, Collodel M, Basso M, Rubini J, Gontier D, Carrère J: [Revision of infected total hip prostheses by ablation reimplantation of an uncemented prosthesis: 57 case reports] [in French]. Rev Chir Orthop Reparatrice Appar Mot 1999, 85:337-348.

38. Oussedik SI, Dodd MB, Haddad FS: Outcomes of revision total hip replacement for infection after grading according to a standard protocol. J Bone Joint Surg Br 2010, 92:1222-1226.

39. Sanzén L, Carlsson A, Josefsson G, Lindberg LT: Revision operations on infected total hip arthroplasties: two- to nine-year follow-up study. Clin Orthop Relat Res 1988, 229:165-172.

40. Vielpeau C, Lortat-Jacob A: [Management of the infected hip prostheses] [in French]. Rev Chir Orthop Reparatrice Appar Mot 2002, 88(Suppl 1):159-216

41. Elson RA: Exchange arthroplasty for infection: perspectives from the United Kingdom. Orthop Clin North Am 1993, 24:761-767.

42. Carlsson A, Josefsson G, Lindberg L: Revision with gentamicinimpregnated cement for deep infections in total hip arthroplasties. $J$ Bone Joint Surg Am 1978, 60:1059-1064.

43. Jämsen E, Stogiannidis I, Malmivaara A, Pajamäki J, Puolakka T, Konttinen YT: Outcome of prosthesis exchange for infected knee arthroplasty: the effect of treatment approach. Acta Orthop 2009, 80:67-77.

44. Wilson PD, Aglietti P, Salvati EA: Subacute sepsis of the hip treated by antibiotics and cemented prosthesis. J Bone Joint Surg Am 1974, 56:879-898.

45. Wylde V, Blom AW: The failure of survivorship. J Bone Joint Surg Br 2011, 93:569-570.

46. Leung F, Richards CJ, Garbuz DS, Masri BA, Duncan CP: Two-stage total hip arthroplasty: how often does it control methicillin-resistant infection? Clin Orthop Relat Res 2011, 469:1009-1015.

47. Jung J, Schmid NV, Kelm J, Schmitt E, Anagnostakos K: Complications after spacer implantation in the treatment of hip joint infections. Int J Med Sci 2009, 6:265-273.

48. Department of Health, National Health Service (NHS) Trust: Confirmation of Payment by Results (PbR) Arrangements for 2010-11.[http://www.dh.gov. uk/prod_consum_dh/groups/dh_digitalassets/@dh/@en/@ps/documents/ digitalasset/dh_112970.pdf]

49. Riley RD, Lambert PC, Abo-Zaid G: Meta-analysis of individual participant data: rationale, conduct, and reporting. BMJ 2010, 340:521-525.

50. Shrier I, Platt RW, Steele RJ: Mega-trials vs. meta-analysis: precision vs. heterogeneity? Contemp Clin Trials 2007, 28:324-328.

\section{Pre-publication history}

The pre-publication history for this paper can be accessed here: http://www.biomedcentral.com/1741-7015/10/18/prepub

doi:10.1186/1741-7015-10-18

Cite this article as: Beswick et al:: What is the evidence base to guide surgical treatment of infected hip prostheses? Systematic review of longitudinal studies in unselected patients. BMC Medicine 2012 10:18. 